\title{
Mental Technologies:
}

mental acquisition of information and influence at distance on the behaviour, physiology and emotions of human beings, and on biological and physical targets

\author{
Patrizio Tressoldi* ${ }^{*}$ and Luciano Pederzoli* $\&$ \\ *Science of Consciousness Research Group, Dipartimento di Psicologia Generale, \\ Università di Padova, Italy \\ $\S$ EvanLab, Firenze, Italy
}

Corresponding author:

Patrizio Tressoldi

Dipartimento di Psicologia Generale,

Università di Padova, Italy

Email: Patrizio.tressoldi@unipd.it 


\begin{abstract}
Even though it is still difficult for many to accept that our minds have the ability to influence and acquire information at a distance, that is to say, by unconventional means, there have already been several attempts to apply these abilities.

This paper provides a review of state-of-the-art practical applications of our mind's ability to obtain information at a distance, even from the future, and its ability to influence, always distantly and unconventionally, the behaviour, emotions, and physiology of human beings and biological and physical targets.

Within the rich variety of these applications, some are already common outside the sphere of pure scientific research because their efficacy has by now been validated, while others' applicability still require fine-tuning so that they too, in a not too distant future, become real mental technologies.
\end{abstract}

Keywords: mental interaction at a distance; remote viewing; anticipation. 


\section{INTRODUCTION}

The purpose of this work is to present an updated review of the potential applications of the mind's non-local characteristics. By non-local characteristics we mean the ability to acquire information and interact at a distance, in other words, beyond the scope of our senses and of our bodies, without any direct contact with the information source or the biological/physical targets. A good summary of experimental proofs for their existence can be found in Cardeña (2018).

Even if, for any other phenomenon that can be studied scientifically, proof of its reality and characteristics are never conclusive, we believe that the current state of scientific evidence of nonlocal properties of the mind, is sufficient to delineate the applicatory fields in which they can be used. As we will see, some applications already have proof of efficacy, while others are still at the hypothetical stage.

We will present the applicatory potentials of non-local characteristics of our mind, differentiating those relative to distant acquisition of information from those relative to distant influence on behaviour, physiology, and emotions of human beings, and on biological and physical targets.

\section{INFORMATION ACQUISITION AT A DISTANCE.}

\subsection{Acquisition of information on the identity and location of objects or persons.}

Undoubtedly the most important project demonstrating the human mind's ability to locate and describe the characteristics of distant objects and people is StarGate. This project, from 1972 until 1995 financed by various United States intelligence agencies such as the DIA (Defense Intelligence Agency), the CIA (Central Intelligence Agency) and others, was aimed at obtaining information useful to the government via mental techniques of remote vision. In 2003 a portion of the archived documents relative to this project was declassified and many documents are now available in four volumes published by Ed May and Sonali Marhawa (2018).

It is unknown if these applications are still active due to the classified nature of military programs, but several former participants of this project, and people trained by them in remote vision techniques, offer services to private citizens and companies ranging from identifying energy sources to locating missing persons or things. Some examples of these services can be found at http://www.noreenrenier.com; http://farsight.org/mission.html.

Two other famous projects that also used remote vision techniques for archaeological research are Alexandria and the Deep Quest Project, directed by Stephan Schwartz (https://stephanaschwartz.com), currently still very active. Parts of these projects are described in Schwartz, Mattei, \& Mobius Society (2000).

\subsection{Acquisition of information about future events.}

Given that non-local properties of our minds also allow acquisition of information of future events, unsurprisingly some have tried to see if it was possible to make money, for example, predicting financial trends or lottery numbers. Obviously not all results of these experiences have been released, but the literature cites some positive outcomes (Kolodziejzyk, 2013; Smith, Laham, \& 
Moddel, 2014) and some negative ones (Katz, Grgic, \& Fendley, 2018). Even for this type of experience online training can be found, for example: https://www.appliedprecog.com/mission.

\subsection{Anticipation of positive or negative random events.}

In this case the applicatory aspects relate to the ability to predict beforehand, usually a few seconds before, negative or positive events, so as to avoid the former and experience the latter. These phenomena are still at the proof-of-concept stage, meaning that there is proof of the possibility of practical valid applications. For example, Duma et al. (2017) have shown that in principle it is possible to implement systems to predict traffic accidents by analysing the EEG of drivers. A similar but more theoretical proposal is given by Khoshnoud, Esat, \& de Silva, (2015).

On the other hand, with respect to predicting random events in gambling, Franklin, Baumgart, Schooler, \& Broadway (2014) have analysed the anticipatory EEG activity in a simulation of random dichotomic events such as Red or Black in roulette.

Another example of a device prototype is the Cardio-Alert, presented by Tressoldi, Martinelli, Torre, Zanette, \& Duma, (2015), which uses cardiac rhythm as an indicator of unpleasant or pleasant events, in this case sounds. Still using cardiac rhythm and in particular measuring HeartRate-Variability (HRV) with a common smartphone video camera, Julia Mossbridge has already created and marketed the Choice Compass (http://choicecompass.com), which helps in choosing the better of two options, for example "Should I choose A, or is it better to choose B?". It measures the HRV ahead of time and chooses the one corresponding to the more regular heartbeat.

\subsection{Acquisition of information from discarnate identities or entities.}

The interest in exploring whether or not there is a continuation of our identity after cessation of the body's vital functions, probably dates back to the dawn of humanity and is still highly topical today; consider how many people go to sensitives or mediums seeking communication with the deceased. Luckily scientific research on control of the source of information and its accuracy from mediums had produced interesting results that show some mediums able to garner information in an unconventional manner and that this information cannot always be acquired through mental connection (telepathy) with those seeking consultation (for a summary see Bastos Jr. et al., 2015; Beischel \& Zingrone, 2015). A large part of scientific results in this field can be attributed to Julie Beischel and Mark Boccuzzi of the Winbridge Research Center (Beischel, Boccuzzi, Biuso, \& Rock, 2015; Beischel, Mosher, \& Boccuzzi, 2017).

This type of communication with discarnate entities also offers the possibility of obtaining useful information for the incarnated life. If we consider all the major monotheistic religions, but not limited to these, we find that most of the information which subsequently became humanity's cultural and religious heritage are attributed to communications of spiritual entities with those who were gifted with certain abilities. This is known as "channeling", because the receiver of information uses his/her own voice, or hands if needed, to communicate the message from these entities.

These phenomena are currently very common, as an internet search for "channeling" will verify. Unfortunately this phenomenon is poorly investigated from a scientific point of view (see Wahbeh, Carpenter, \& Radin, 2018) and therefore doubts remain regarding the origin of the information coming out, even if there are already initiatives to make this form of communication technologically advanced, like for example the "SoulPhone" project 
(https://www.thesoulphonefoundation.org). A different approach for verifying the source of channeled information is currently being studied by (Pederzoli \& Tressoldi, in preparation), by inducing hypnosis in the channeler and thus allowing repeated dialogue with the entity giving information, thereby more accurately investigating whether this entity is real or invented based on the channeler's or hypnotist's knowledge.

\section{DISTANT INTERACTION.}

As stated earlier, that which can be called the other side of the coin of the mind's non-local properties involves interacting with, and therefore intentionally influencing, other human beings and biological or physical targets.

\subsection{Effects of distant interaction on the behaviour of human beings.}

Certainly, the most spectacular effects of distant mental interaction on the behaviour of humans are those obtained from the so-called "Maharishi effect", named after Maharishi Mahesh, an Indian yogi who brought transcendental meditation to the west and facilitated the creation of the Maharishi University. The courses in this university range from management to physics and are all inspired by the teachings of this spiritual master. Basically, the Maharishi effect consists of positively modifying the behaviours and negative events of a population through the application of this practice by a number of meditators equal to approximately the square root of $1 \%$ of this population. If, for example, the population to influence is around one million people, it would suffice if the number of meditators were the square of 10,000 , therefore 100 people. To understand the origin of this formula, we refer the reader to an article by Hagelin (1987), in which a physical model of consciousness is illustrated. The deep meditative state reached simultaneously by the meditators, creates a psycho-physical coherence field on the entire population, reducing the number of negative events such as aggression, violence, road accidents, etc. Empirical support for this theory is found in more than 50 studies (Cavanaugh \& Dillbeck, 2017; Dillbeck \& Cavanaugh, 2016, 2017; OrmeJohnson, W., \& Oates, 2009), despite much resistance to the acceptance of these effects as real.

\subsection{Distant interaction on the body's physiology.}

The most well known effects of distant interaction on body physiology are those described as "distant healing" and "intercessory prayer". The difference depends only on the cultural and theoretical model referred to by those wanting to improve the health of people far away; the model can stretch from an energetic-mental one, such as Reiki, to a religious one, such as prayer to Jesus Christ or Mother Mary.

Given the difficulty in carrying out clinical studies that can also control potential placebo effects, evidence to support these distant interactions are not many. The most recent meta-analyses (Astin, Harkness, \& Ernst, 2000; Hodge, 2007; Masters, Spielmans, \& Goodson, 2006) give predictably contradictory results, given the variety of therapeutic approaches and the many types of physical problems as the targets of healing, such as cardiac, renal, etc, as well as mental, for example various psychiatric disturbances etc.

These effects have also been studied on animals, which supposedly are less influenced than humans by conscious or unconscious aspects. For example William Bengston (Bengston, 2012, 2018; 2007), after a prolonged study, managed to demonstrate the healing of laboratory mice which had been injected with lethal cancerous cells, by applying simple mental techniques centred on the intention to heal and a mental connection with the animals to be healed without any direct contact. 
Another research path takes advantage of the distant neurophysiological relationship between two partners, which we can call "Brain-to-Brain interaction at a distance", consisting of attempting to transmit ON/OFF binary signals by analysing the correlation between the EEG activity of the stimulated partner and the other distant but mentally-connected partner. Preliminary data obtained by Giroldini, Pederzoli, Bilucaglia, Prati, \& Tressoldi, (2018) e Tressoldi et al., (2014) are promising, but there is still much work to be done to extract the weak EEG signal of the receiving partner, who is only linked mentally.

\subsection{Distant interaction with biological targets.}

Contrary to mental interaction with human health, proof regarding for example favouring the growth of organic material, such as plant seeds and various cell cultures, are more consistent. In the latest meta-analysis presented by Roe, Sonnex, \& Roxburgh, (2014), 49 of these experiments are taken into consideration.

An interesting development in this field is the possibility of "activating" certain materials, such as cotton, which, when put in contact with sick cells, even at a distance in time, can facilitate healing. A recent example of this effect is documented by Beseme, Bengston, Radin, Turner, \& McMichael, (2018).

Some odd applications of the ability to influence biological targets have shown that it is possible to positively influence the effects of food and drink on the consumer. For example Radin, Hayssen, \& Walsh (2007) and Shiah \& Radin, (2013) have demonstrated that consumers of chocolate and tea which had been impressed by a group of meditators with the intention of inducing positive emotions and psycho-physical well-being reported having better moods compared to others consuming the same, but non-influenced, substances.

\section{4 Distant interaction with physical targets.}

The field of distant mental interaction on physical targets, for example random number generators, photon detectors etc, is at the moment that with the least scientific evidence for practical applications. A prototype device which exploits these human mind potentialities, called "MindSwitch", was presented by Tressoldi, Pederzoli, \& Melloni, (2015). Essentially, when the software of this portable device senses that the data it receives from a random number generator (RNG) violate a particular entropy level (randomness falls below a certain threshold level), it emits a signal that can act on any electric or electronic device connected to it, even via WiFi. The tricky problem to solve is that of distinguishing violations of random entropy from those induced by distant mental interaction in order to reduce false positive signals.

In a similar application, in this case used to move a mini robot connected to an RNG was presented by Jahn, Dunne, Acunzo, \& Hoeger, (2007), but unfortunately has not been further developed.

Another interesting application is the attempt to visualise artistically the changes in the activity of a RNG, still using the mind to induce the changes. Marc Boccuzzi, (2015) of the Winbridge Research Center created a software program able to process the changes induced by sending positive or negative emotions to an RNG to create PsiForms, in other words psych-forms such as that shown in Figure 1. 


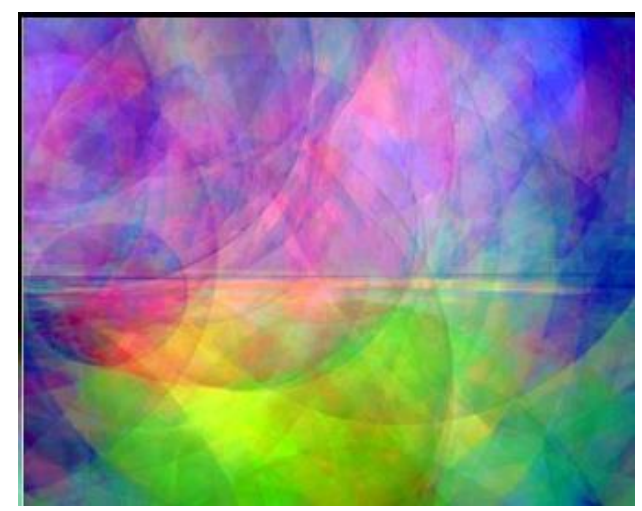

Figure 1: Example of PsiForm

Mind Lamp ${ }^{\mathrm{TM}}$ on the other hand is a commercial product that uses an RNG to change the colour of a lamp. See Figure 2.

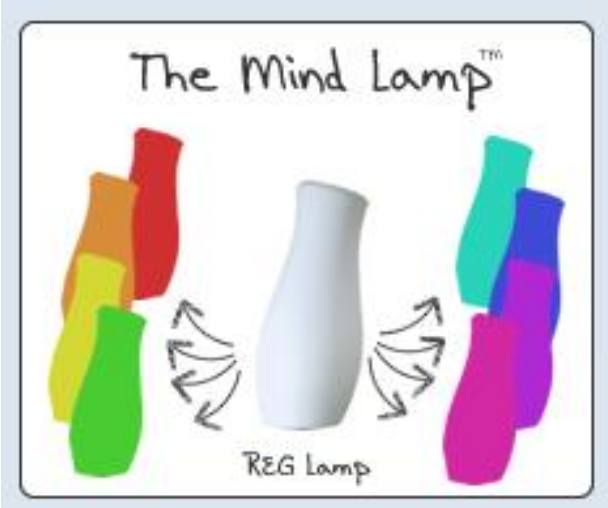

Figure 2: Example of Mind Lamp ${ }^{\mathrm{TM}}$ (centre) and the colours it can change to.

According to the lamp's developers it is possible to influence the activity of the RNG inside it to obtain the desired colour. Nonetheless for now there is no proof for the efficacy of this type of mental influence.

Another application associated with distant vision (see paragraphs 2.1 and 2.2) is that created by Garret Moddel and named Machine-Mediated Remote Viewing. In essence, during a distant viewing experiment, an RNG beside the participant is activated and its output is used to create an image using the raster technique (scanning parallel lines, as in TVs). This image is then compared with other similar images that are not associated with the distant target image to be viewed, in order to identify the target. Preliminary data presented by Machine-Mediated Remote Viewing are encouraging. An example is given in Figure 3.
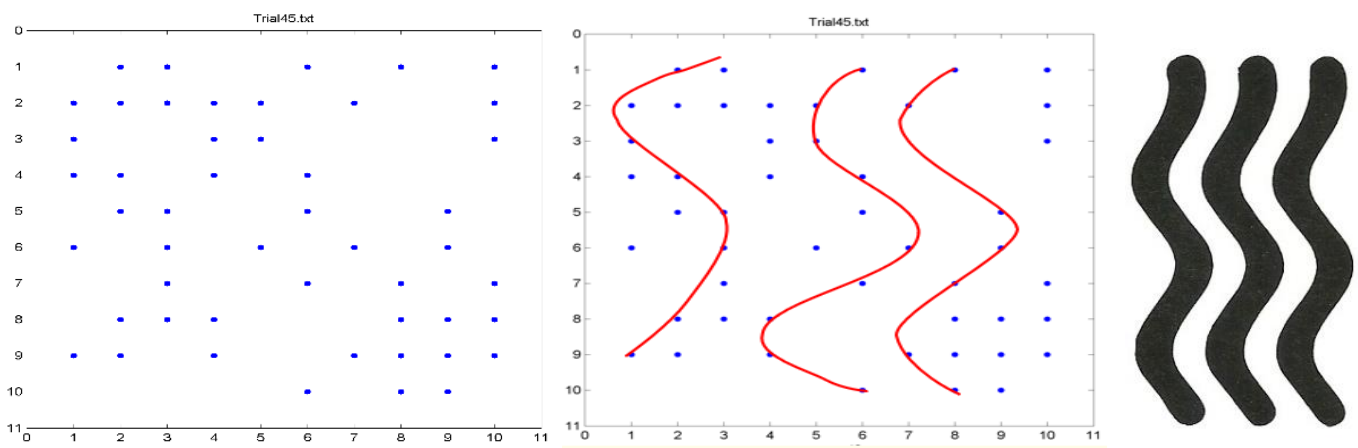

Figure 2: On the left is the output signal from the random number generator; centre is the judges' reconstruction; on the right is the target. 


\section{FINAL DISCUSSION}

From this overview of the practical applications of the mind's non-local characteristics we see that the use of some of these is already sufficiently common even outside the research field; we refer to, for example, the use of distant vision and the so-called "Maharishi effect", while others are spreading because scientific evidence for them is already solid, as in the case of interaction with biological targets. For the remainder, however, more detailed studies and improvements are required to make them applicable outside the research field, some examples being Mind-to-Mind transmission or interaction with physical targets.

A certainty, in our opinion, is that an interesting picture is emerging of the potentialities of the mind, most of which are still unknown. Looking at the not too distant future, if these applications are perfected, we can avail ourselves of "mental technologies" which, if used for the common good, will bring great personal and collective benefits.

A 'futuristic' video relative to these technologies can be viewed at: https://youtu.be/4 VcGsDeurw. 


\section{References}

Astin, J. A., Harkness, E., \& Ernst, E. E. (2000). The efficacy of distant healing: a systematic review of randomized trials. Annals of Internal Medicine, 132(11), 903-910.

Bastos Jr., M. A. V., Bastos, P. R. H. de O., Gonçalves, L. M., Osório, I. H. S., Lucchetti, G., Bastos Jr., M. A. V., ... Lucchetti, G. (2015). Mediumship: review of quantitatives studies published in the 21st century. Archives of Clinical Psychiatry (São Paulo), 42(5), 129-138. https://doi.org/10.1590/0101-60830000000063

Beischel, J., Boccuzzi, M., Biuso, M., \& Rock, A. J. (2015). Anomalous information reception byresearch mediums under blinded conditions II: replication and extension. EXPLORE: The Journal of Science and Healing, 11(2), 136-142. https://doi.org/10.1016/J.EXPLORE.2015.01.001

Beischel, J., Mosher, C., \& Boccuzzi, M. (2017). Quantitative and qualitative analyses of mediumistic and psychic experiences. Threshold: Journal of Interdisciplinary Consciousness Studies, 1(2), 51-91.

Beischel, J., \& Zingrone, N. (2015). Mental mediumship. In E. Cardeña, J. Palmer, \& D. Marcusson-Clavertz (Eds.), Parapsychology: A handbook for the 21 st century (pp. 301-313). Jefferson, NC: McFarland.

Bengston, W. (2007). Commentary: A Method Used to Train Skeptical Volunteers to Heal in an Experimental Setting. The Journal of Alternative and Complementary Medicine, 13(3), 329332. https://doi.org/10.1089/acm.2007.6403

Bengston, W. (2012). Spirituality, connection, and cealing with intent: reflections on cancer experiments on laboratory mice. In L. . Miller (Ed.), The Oxford Handbook of Psychology and Spirituality (pp. 548-557). Oxford.

Bengston, W. (2018). Questioning the Importance of Conscious Awareness in Alternative Healing. Mindfield, 6-11.

Beseme, S., Bengston, W., Radin, D., Turner, M., \& McMichael, J. (2018). Transcriptional Changes in Cancer Cells Induced by Exposure to a Healing Method. Dose-Response, 16(3), 18. https://doi.org/10.1177/1559325818782843

Boccuzzi, M. (2015). Visualizing Intention: Art informed by Science. Tucson, AZ: The Windbridge Institute, LLC.

Cardeña, E. (2018). The experimental evidence for parapsychological phenomena: A review. American Psychologist, 73(5), 663-677. https://doi.org/10.1037/amp0000236

Cavanaugh, K. L., \& Dillbeck, M. C. (2017). The Contribution of Proposed Field Effects of Consciousness to the Prevention of US Accidental Fatalities: Theory and Empirical Tests. Journal of Consciousness Studies, 24(1-2), 53-86.

Dillbeck, M. C., \& Cavanaugh, K. L. (2016). Societal Violence and Collective Consciousness. SAGE Open, 6(2), 1-16. https://doi.org/10.1177/2158244016637891

Dillbeck, M. C., \& Cavanaugh, K. L. (2017). Group Practice of the Transcendental Meditation® and TM-Sidhi ${ }^{\circledR}$ Program and Reductions in Infant Mortality and Drug-Related Death. SAGE Open, 7(1), 1-15. https://doi.org/10.1177/2158244017697164

Duma, G. M., Vernon, D., Mento, G., Manari, T., Martinelli, M., \& Tressoldi, P. (2017). Driving with Intuition: A Preregistered Study about the EEG Anticipation of Simulated Random Car Accidents. PLOS ONE. https://doi.org/10.1371/journal.pone.0170370

Franklin, M. S., Baumgart, S. L., Schooler, J. W., \& Broadway, J. M. (2014). Future directions in precognition research: more research can bridge the gap between skeptics and proponents. Frontiers in Psychology, 5 :907. https://doi.org/10.3389/fpsyg.2014.00907

Giroldini, W., Pederzoli, L., Bilucaglia, M., Prati, E., \& Tressoldi, P. (2018). Exploring the Brainto-Brain interaction at a distance: a global or differential relationship? https://doi.org/10.31234/OSF.IO/Z8D65

Hodge, D. R. (2007). A Systematic Review of the Empirical Literature on Intercessory Prayer. Research on Social Work Practice, 17(2), 174-187. https://doi.org/10.1177/1049731506296170 
Jahn, R. G., Dunne, B. J., Acunzo, D. J., \& Hoeger, E. S. (2007). Response of an REG-driven robot to operator intention. Journal of Scientific Exploration, 21(1), 27-46.

Katz, D. L., Grgic, I., \& Fendley, T. W. (2018). An Ethnographical Assessment of Project Firefly: A Yearlong Endeavor to Create Wealth by Predicting FOREX Currency Moves with Associative Remote Viewing. Journal of Scientific Exploration, 32(1), 21-54.

Khoshnoud, F., Esat, I. I., \& de Silva, C. W. (2015). Bioinspired Psi intelligent control for autonomous vehicles. In 2015 10th International Conference on Computer Science \& Education (ICCSE) (pp. 208-212). IEEE. https://doi.org/10.1109/ICCSE.2015.7250244

Kolodziejzyk, G. (2013). Greg Kolodziejzyk’s 13-year associative remote viewing experiment results. Journal of Parapsychology, 76, 349-368.

Masters, K. S., Spielmans, G. I., \& Goodson, J. T. (2006). Are there demonstrable effects of distant intercessory prayer? A meta-analytic review. Annals of Behavioral Medicine, 32(1), 21-26. https://doi.org/10.1207/s15324796abm3201_3

May, E. C., \& Marwaha, S. B. (2018). The Star Gate archives : reports of the United States government sponsored Psi program, 1972-1995. Jefferson, NC, USA: McFarland.

Orme-Johnson, W., D., \& Oates, R. M. (2009). A Field-Theoretic View of Consciousness : Reply to Critics. Journal of Scientifi c Exploration, 23(2), 139-166.

Pederzoli, L., \& Tressoldi, P. E. (in preparation). Channeling Interview: how to verify channeling information in hypnosis.

Radin, D., Hayssen, G., \& Walsh, J. (2007). Effects of intentionally enhanced chocolate on mood. EXPLORE: The Journal of Science and Healing, 3(5), 485-492. https://doi.org/10.1016/J.EXPLORE.2007.06.004

Roe, C. A., Sonnex, C., \& Roxburgh, E. C. (2014). Two meta-analyses on noncontact healing studies. Explore: The Journal of Science and Healing, 11, 11-23. https://doi.org/10.1016/j.explore.2014.10.001

Schwartz, S. A., Mattei, R. J. De, \& Society, T. M. (2000). The discovery of an American brig: fieldwork involving applied remote viewing including a comparison with electronic remote sensing. Archaeology, 73-78.

Shiah, Y.-J., \& Radin, D. (2013). Metaphysics of the Tea Ceremony: A randomized trial investigating the roles of intention and belief on mood while drinking tea. EXPLORE: The Journal of Science and Healing, 9(6), 355-360. https://doi.org/10.1016/J.EXPLORE.2013.08.005

Smith, C. C., Laham, D., \& Moddel, G. (2014). Stock Market Prediction Using Associative Remote Viewing. Journal of Scientific Exploration, 28(1), 7-16.

Tressoldi, P. E., Martinelli, M., Torre, J., Zanette, S., \& Duma, G. M. (2015). CardioAlert: An heart rate based decision support system for improving choices related to negative or positive future events. SSRN Electronic Journal. https://doi.org/10.2139/ssrn.2604206

Tressoldi, P. E., Pederzoli, L., \& Melloni, S. (2015). Mindswitch: A first prototype of a new generation of Mind-Controlled Technologies. SSRN Electronic Journal. https://doi.org/10.2139/ssrn.2656281

Tressoldi, P., Pederzoli, L., Bilucaglia, M., Caini, P., Fedele, P., Ferrini, A., ... Accardo, A. (2014). Brain-to-Brain (mind-to-mind) interaction at distance: a confirmatory study. F1000Research, 3. https://doi.org/10.12688/f1000research.4336.3

Wahbeh, H., Carpenter, L., \& Radin, D. (2018). A mixed methods phenomenological and exploratory study of channeling. Journal of the Society for Psychical Research, 82(3), 129147. 